\title{
Take-home naloxone programs for suspected opioid overdose in community settings: a scoping umbrella review
}

\author{
Amina Moustaqim-Barrette', Damon Dhillon², Justin $\mathrm{Ng}^{1}$, Kristen Sundvick ${ }^{2}$, Farihah Ali ${ }^{3}$, Tara Elton-Marshall ${ }^{3,4,5}$,
} Pamela Leece ${ }^{5,6}$, Katherine Rittenbach ${ }^{7,8,9}$, Max Ferguson $^{1}$ and Jane A. Buxton ${ }^{1,10^{*}}$

\begin{abstract}
Background: Opioid related overdoses and overdose deaths continue to constitute an urgent public health crisis. The implementation of naloxone programs, such as 'take-home naloxone' (THN), has emerged as a key intervention in reducing opioid overdose deaths. These programs aim to train individuals at risk of witnessing or experiencing an opioid overdose to recognize an opioid overdose and respond with naloxone. Naloxone effectively reverses opioid overdoses on a physiological level; however, there are outstanding questions on community THN program effectiveness (adverse events, dosing requirements, dose-response between routes of administration) and implementation (accessibility, availability, and affordability). The objective of this scoping review is to identify existing systematic reviews and best practice guidelines relevant to clinical and operational guidance on the distribution of THN.
\end{abstract}

Methods: Using the Arksey \& O'Malley framework for scoping reviews, we searched both academic literature and grey literature databases using keywords (Naloxone) AND (Overdose) AND (Guideline OR Review OR Recommendation OR Toolkit). Only documents which had a structured review of evidence and/or provided summaries or recommendations based on evidence were included (systematic reviews, meta-analyses, scoping reviews, short-cut or rapid reviews, practice/clinical guidelines, and reports). Data were extracted from selected evidence in two key areas: (1) study identifiers; and (2) methodological characteristics.

Results: A total of 47 articles met inclusion criteria: 20 systematic reviews; 10 grey literature articles; 8 short-cut or rapid reviews; 4 scoping reviews; and 5 other review types (e.g. mapping review and comprehensive reviews). The most common subject themes were: naloxone effectiveness, safety, provision feasibility/acceptability of naloxone distribution, dosing and routes of administration, overdose response after naloxone administration, costeffectiveness, naloxone training and education, and recommendations for policy, practice and gaps in knowledge.

(Continued on next page)

\footnotetext{
* Correspondence: jane.buxton@bccdc.ca

1 BC Centre for Disease Control, Vancouver, BC, Canada

${ }^{10} \mathrm{School}$ of Population and Public Health, University of British Columbia, Vancouver, BC, Canada

Full list of author information is available at the end of the article
}

(c) Her Majesty the Queen in Right of Canada. 2021 Open Access This article is licensed under a Creative Commons Attribution 4.0 International License, which permits use, sharing, adaptation, distribution and reproduction in any medium or format, as long as you give appropriate credit to the original author(s) and the source, provide a link to the Creative Commons licence, and indicate if changes were made. The images or other third party material in this article are included in the article's Creative Commons licence, unless indicated otherwise in a credit line to the material. If material is not included in the article's Creative Commons licence and your intended use is not permitted by statutory regulation or exceeds the permitted use, you will need to obtain permission directly from the copyright holder. To view a copy of this licence, visit http://creativecommons.org/licenses/by/4.0/. The Creative Commons Public Domain Dedication waiver (http:// creativecommons.org/publicdomain/zero/1.0/) applies to the data made available in this article, unless otherwise stated in a credit line to the data. 
(Continued from previous page)

Conclusions: Several recent systematic reviews address the effectiveness of take-home naloxone programs, naloxone dosing/route of administration, and naloxone provision models. Gaps remain in the evidence around evaluating cost-effectiveness, training parameters and strategies, and adverse events following naloxone administration. As THN programs continue to expand in response to opioid overdose deaths, this review will contribute to understanding the evidence base for policy and THN program development and expansion.

Keywords: Naloxone, Opioid overdose, Fentanyl, Opioids, Opiates

\section{Introduction}

Opioid related overdoses and overdose deaths continue to present an urgent public health crisis worldwide. The World Health Organisation (WHO) estimates 115,000 people died from opioid overdose in 2017 [1]. In Canada, 16,364 people died of opioid-related overdoses between January 2016 and March 2020 [2], and the number of opioid-related deaths continues to rise [2]. In 2017, 46,802 drug overdose deaths in the United States involved opioids [3]. Spikes in opioid overdose deaths are related to both prescription opioids and to the emergence of the synthetic opioid fentanyl and its analogues in the unregulated market $[4,5]$. Fentanyl is marked by high lipid solubility, leading to faster penetration of the blood-brain barrier and rapid respiratory depression compared to other opioids [6], necessitating rapid response in cases of overdose. The distribution of naloxone through programs colloquially referred to as 'takehome naloxone' (THN) has emerged as a key intervention to reduce opioid overdose deaths.

Opioids are substances derived from the opium poppy (natural opiates) or chemically synthesized, and often used or prescribed for pain [1]. Naloxone is a $\mu$-opioid receptor antagonist effective at temporarily reversing the symptoms of opioid toxicity and life-threatening respiratory depression [7]. While naloxone has been used reliably in hospital settings to reverse opioid overdoses for over 50 years [8], the advent of THN programs and naloxone distribution and use by community members has expanded widely in more recent years. The first community-based naloxone projects in the United States and Europe started in the 1990s [9-11]. Given the dramatic increase in fatal opioid overdoses over the past decade in the United States and Canada, these jurisdictions began to prioritise increased access to naloxone and overdose education. In many countries worldwide, naloxone is only available to health professionals, although some jurisdictions are adopting policies to make the antidote more widely accessible [1]. Currently, naloxone is available in pharmacies without prescription in Australia, Canada, Italy, the United Kingdom of Great Britain and Northern Ireland, and Ukraine [1]. In Canada, two provincial programs (British Columbia and Ontario) were introduced before 2015, with the remaining eleven provinces and territories introducing programs between 2015 and 2018 [12]. As of December 2018, more than 590,000 naloxone kits had been distributed across Canada [2]. Preliminary evidence suggests that THN has helped avert thousands of additional opioid overdose deaths $[13,14]$.

Generally, THN programs aim to equip individuals who are at risk of witnessing or experiencing an opioid overdose with naloxone and to train them in overdose recognition and response. In Canada, THN kits generally include a carrying case, non-latex gloves, alcohol swabs, a face shield for providing rescue breaths, instructions on overdose response, and either injectable or nasal formulations of naloxone, depending on the province [12]. Preliminary evidence suggests that THN has been an effective intervention at preventing opioid overdose deaths $[9,14,15]$. However, there are outstanding questions regarding THN program effectiveness and implementation, including adverse events after naloxone administration, naloxone dosing requirements and doseresponse between routes of administration, and access (including accessibility, availability, and affordability).

We conducted an umbrella scoping review (review of reviews) of the literature to characterise the existing knowledge base related to the use of naloxone for reversal of opioid overdose. The current paper will help identify gaps in the current evidence needed to inform clinical and operational guidance. Up-to-date guidance is critically needed to assist healthcare providers, policy makers, and program administrators in decisions regarding naloxone access, use, distribution, and training of bystanders. The results from this review can similarly be applied to understand the scope of knowledge relevant to standards for naloxone distribution and administration in other jurisdictions.

\section{Methods \\ Design}

The umbrella scoping review was conducted in adherence with the Arksey \& O'Malley framework for scoping reviews [16]. Updates to this original framework by Levac et al. [17] were used to guide the methodology of this scoping review. Findings are reported in accordance with the Preferred Reporting Items for Systematic 
Reviews and Meta-Analyses (PRISMA) checklist for Scoping Reviews guidelines [18].

\section{Eligibility criteria}

We confined our search to sources that described the use of naloxone for opioid overdose events, in any context that could reasonably relate to its distribution in the community for use by members of the general public. We included documents that had a structured review of evidence and/or provided summaries or recommendations based on evidence. This included systematic reviews, meta-analyses, scoping reviews, short or rapid reviews, practice guidelines, clinical guidelines, various reports, and working papers. We did not limit our search by timeframe - all databases of published literature were searched from database inception date to present. Sources were limited to those published or translated into English or French.

Due to the variability in the comprehensiveness and objectiveness of analysis in narrative reviews, these were excluded. Grey literature sources were limited to those published by a government (municipal, provincial or federal level), non-profit organisation, academic organisation, or professional medical society - documents published by private businesses or industry were excluded. No exclusions were made based on geographic location.

\section{Information sources}

A search strategy was developed and refined with the help of a research librarian. Academic literature databases and grey literature databases were searched. We searched the following databases for peer-reviewed literature: Ovid Medline, Embase, the Cumulative Index to Nursing and Allied Health Literature (CINAHL), PsycINFO, Prospero, and Epistemonikos.

We defined grey literature as literature not published in books or journals [19]. The process outlined by Godin et al. [20] was used to identify evidence from the grey literature. This process incorporates four different searching strategies: 1) Searching grey literature databases, 2) using Customized Google searches, 3) searching targeted websites, and 4) consultation with content experts. Grey literature databases included Guidelines International Network (GIN), Open Grey: System for Information on Grey Literature of Medicine, and Grey Literature Report. Customized Google searches were performed, and the first 100 hits evaluated. Targeted websites included government websites in Canada, the United States, Europe, and Australia, reflecting regions affected by the opioid crisis related to regional drug supply [21]. Nongovernmental and think tank websites including the Bill and Melinda Gates Foundation, WHO, United Nations, Canadian Centre on Substance Use and Addiction
(CCSA) and the Canadian Agency for Drugs and Technology in Health (CADTH) were also searched. A list of content experts was developed and a request for referred literature and projects in progress was sent, with follow up at two weeks.

\section{Search}

The following search terms were used and modified, if necessary, for the search: (Naloxone) AND (Overdose) AND (Guideline OR Review OR Recommendation OR Toolkit). Searches were performed from database inception to April 2020 and updated in June 2020. See Table 1 for an example search strategy in Ovid Medline.

Searching the grey literature involves using databases with a wide variance in search functionalities and filters available for retrieving results. As such, search terms were adapted to fit each database and its usability.

\section{Selection of evidence}

All of the search results were exported into the reference manager Zotero [22], and then added to the systematic review software Covidence [23]. Duplicates were identified and removed. In cases where reports or evidence reviews were updates of previous reports or reviews, only the most recent version was included. Two reviewers $(\mathrm{AMB}$ and $\mathrm{JN})$ independently screened published articles based on information contained in the title, abstracts, and key words. For any uncertainties or disagreements, articles were discussed by both reviewers until agreement was reached. For grey literature searches, one reviewer (AMB) reviewed the title and summary lines from each entry for relevance. Full grey literature reviews were then conducted by the same two independent reviewers (AMB and JN), and reasons for exclusion were recorded. Where full documents could not be accessed, our team contacted the authors with a request for the document or an update on the status of the title. Conflicts were again re-evaluated by both reviewers and each resolved through discussion. The reference lists of included articles were then checked (citation chained). In cases where Covidence failed to remove duplicates, duplicates were removed during full text screening. Quality appraisal was not performed or used for study selection.

\section{Data extraction}

Data were extracted using a structured data abstraction form designed in REDCap, a web-based data collection tool that allows users to build and manage databases [24]. The abstraction form was first piloted by four independent reviewers (AMB, JN, DD, and $\mathrm{KS}$ ) using a total of three selected articles each, and revisions were made through consensus discussion. Three key areas were used for extraction: [25] Study identifiers (article title; 
Table 1 Example search strategy - Medline Ovid

\begin{tabular}{|c|c|c|}
\hline & Ovid MEDLINE(R) and Epub Ahead of Print, In-Process \& Other Non-Indexed Citations, Daily and Ver & 946 to \\
\hline$\#$ & Searches & Results \\
\hline 1 & Naloxone/ & 18,648 \\
\hline 2 & $\begin{array}{l}\text { (naloxon* or narcan*).mp. [mp = title, abstract, original title, name of substance word, subject heading } \\
\text { word, floating sub-heading word, keyword heading word, organism supplementary concept word, } \\
\text { protocol supplementary concept word, rare disease supplementary concept word, unique identifier, } \\
\text { synonyms] }\end{array}$ & 27,182 \\
\hline 3 & Drug Overdose/ & 11,165 \\
\hline 4 & $\begin{array}{l}\text { overdos*.mp. [mp = title, abstract, original title, name of substance word, subject heading word, floating } \\
\text { sub-heading word, keyword heading word, organism supplementary concept word, protocol supplementary } \\
\text { concept word, rare disease supplementary concept word, unique identifier, synonyms] }\end{array}$ & 24,133 \\
\hline 5 & 1 or 2 & 27,182 \\
\hline 6 & 3 or 4 & 24,133 \\
\hline 7 & 5 and 6 & 1550 \\
\hline 8 & limit 7 to (english or french) & 1527 \\
\hline
\end{tabular}

journal title; authors; country of the study; language; publication year) [1]; methodological characteristics (study design; study objective, research question, or hypothesis; study population; data sources; statistical analyses) [2]; main outcomes measured. Some articles constituted larger reviews of harm reduction interventions. For all articles, the number of primary studies specifically related to naloxone was extracted. Of these, the number of randomized controlled trials (RCTs) evaluated by the articles was also examined.

Data were extracted by authors AMB and JN and validated by authors KS and DD. Any conflicts were resolved through discussion. Once finalised, data from REDCap was exported, cleaned, and analysed using $\mathrm{R}$ version 3.5.3 [26].

\section{Results}

\section{Overview}

A total of 127 articles underwent full-text review, and 47 unique articles ultimately met the inclusion criteria - see Fig. 1 for a PRISMA flow diagram on evidence selection. This review sought to identify evidence syntheses which used systematic methods to identify primary research. As such, no primary research articles were included in the review. The most common reason for exclusion was that the study did not provide structured review of evidence and/ or did not provide summaries or recommendations based on evidence- most often excluded studies were narrative reviews.

Methodological characteristics of the articles included can be found in Table 2 and Table 3. A total of 20 systematic reviews were identified, 10 evidence syntheses from the grey literature, 8 'short-cut' or rapid reviews, 4 scoping reviews, and 5 other reviews (e.g. mapping review and comprehensive reviews) types. Of the systematic reviews, five articles used meta-analyses, and 16 articles examined results from Randomized Controlled Trials (RCTs). During data extraction, all articles were categorised by reviewers into larger subject themes. Table 4 provides included literature by subject theme. The subject themes which arose most frequently were: naloxone dosing and routes of administration $(n=14,29.8 \%)$, provision, feasibility, and acceptability of naloxone distribution $(n=13,27.7 \%)$, effectiveness of naloxone and take-home naloxone for opioid overdose reversal $(n=10,21.3 \%)$, overdose response after naloxone administration $(n=6,12.8 \%)$, naloxone training and education $(n=6,12.8 \%)$, recommendations for policy, practice and gaps in knowledge $(n=4,8.5 \%)$, naloxone safety (harms or adverse events related to naloxone administration) $(n=3,6.4 \%)$, and cost-effectiveness $(\mathrm{n}=3$, 6.4\%).

Figure 2 presents the distribution of included articles according to year of publication and geographic location of origin. A total of 12 articles originated from Europe, 11 from Canada, 20 from the United States, two from Australia, and two from Iran. Reflecting the historical emergence of THN programs across jurisdictions, the earliest evidence syntheses emerged from Europe in early 2000. From 2015 to 2020 , there was a notable increase in the number of articles addressing the use of naloxone in opioid overdose, with 38 evidence syntheses $(80.6 \%)$ published in the last five years.

\section{Naloxone and THN program effectiveness in treatment of opioid overdose}

Ten systematic reviews examined the effectiveness of naloxone or THN programs for the treatment of opioid overdose $[9,11,27,29,31,33,37,38,45,51,61$, 64]. Bahji et al. was the only systematic review to examine the effectiveness of naloxone as a candidate drug for opioid overdose reversal [27]. Another two 


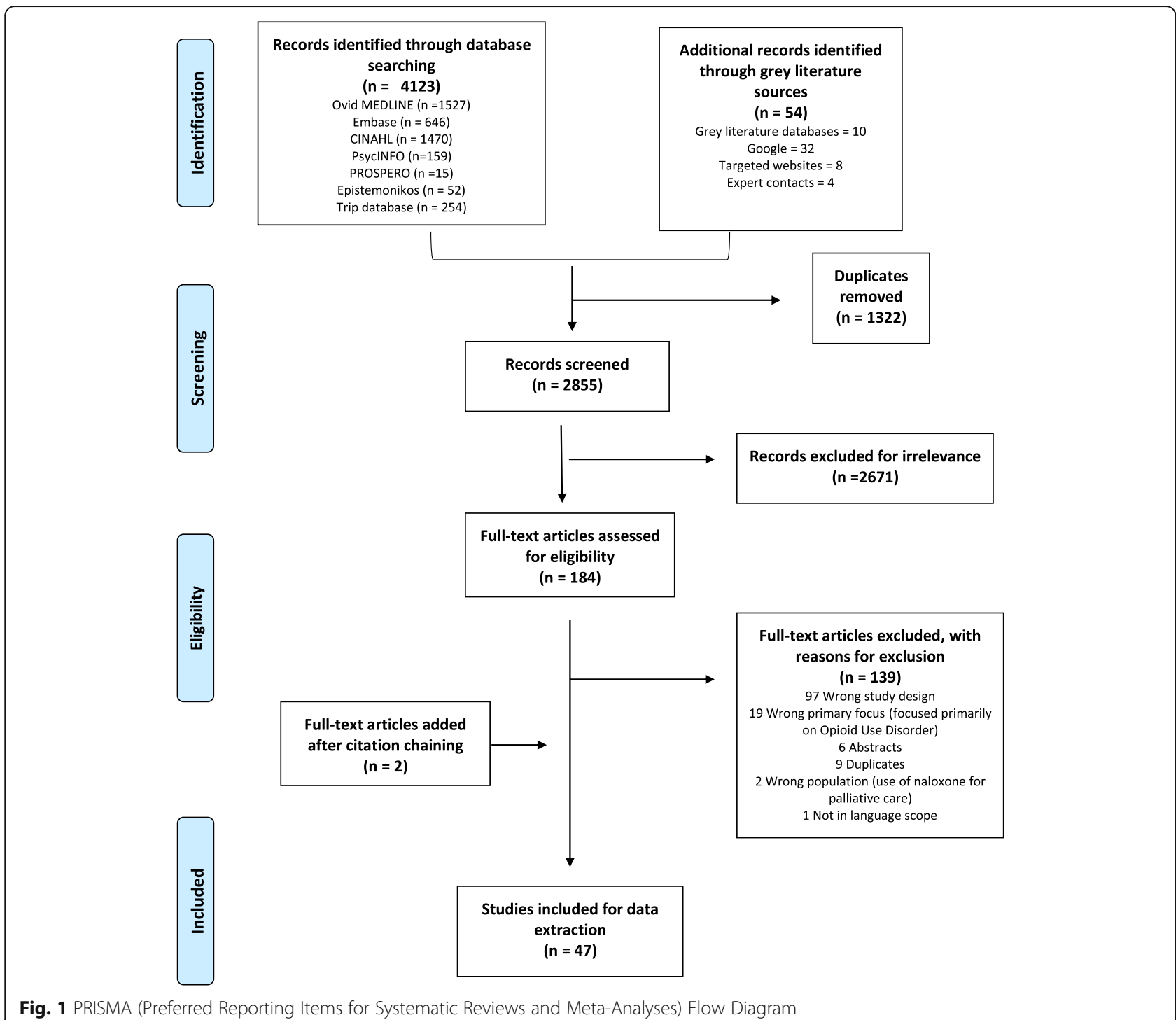

reports sought to examine the clinical effectiveness of naloxone administered in pre-hospital, community, or home settings [61, 64].

A systematic review by McDonald and Strang [9] investigated the relationship between THN programs and opioid overdose mortality using Bradford-Hill criteria (minimal criterion for establishing causal inference). Several studies investigated the association between naloxone distribution and overdose reversal $[31,38]$ or a reduction in overdose mortality $[11,29]$.

One article used meta-analyses to generate an estimate of the effectiveness of bystander naloxone administration and overdose education programs on overdose recovery across nine primary articles [33]. One rapid review was carried out to establish whether the training of people who use intravenous drugs in the use of naloxone reduces mortality from opioid overdose [51].

\section{Provision, feasibility, and acceptability of naloxone} distribution

Of the 13 articles that evaluated outcomes related to the provision, feasibility, and acceptability theme, several reviews evaluated naloxone provision in a specific setting. Thakur et al. performed a systematic review examining pharmacy dispensing and distribution of naloxone [43], while Muzyk et al. [47] and Nielsen et al. [48] performed scoping reviews related to pharmacy naloxone provision and pharmacist attitudes. Gunn et al. assessed distribution of naloxone from emergency departments [35], and Behar et al. assessed acceptability and feasibility of naloxone prescribing to patients in primary care settings [28]. One mapping review assessed evidence on THN distribution from correctional facilities to identify further research needs [67], and two rapid reviews assessed attitudes and experiences related to naloxone 


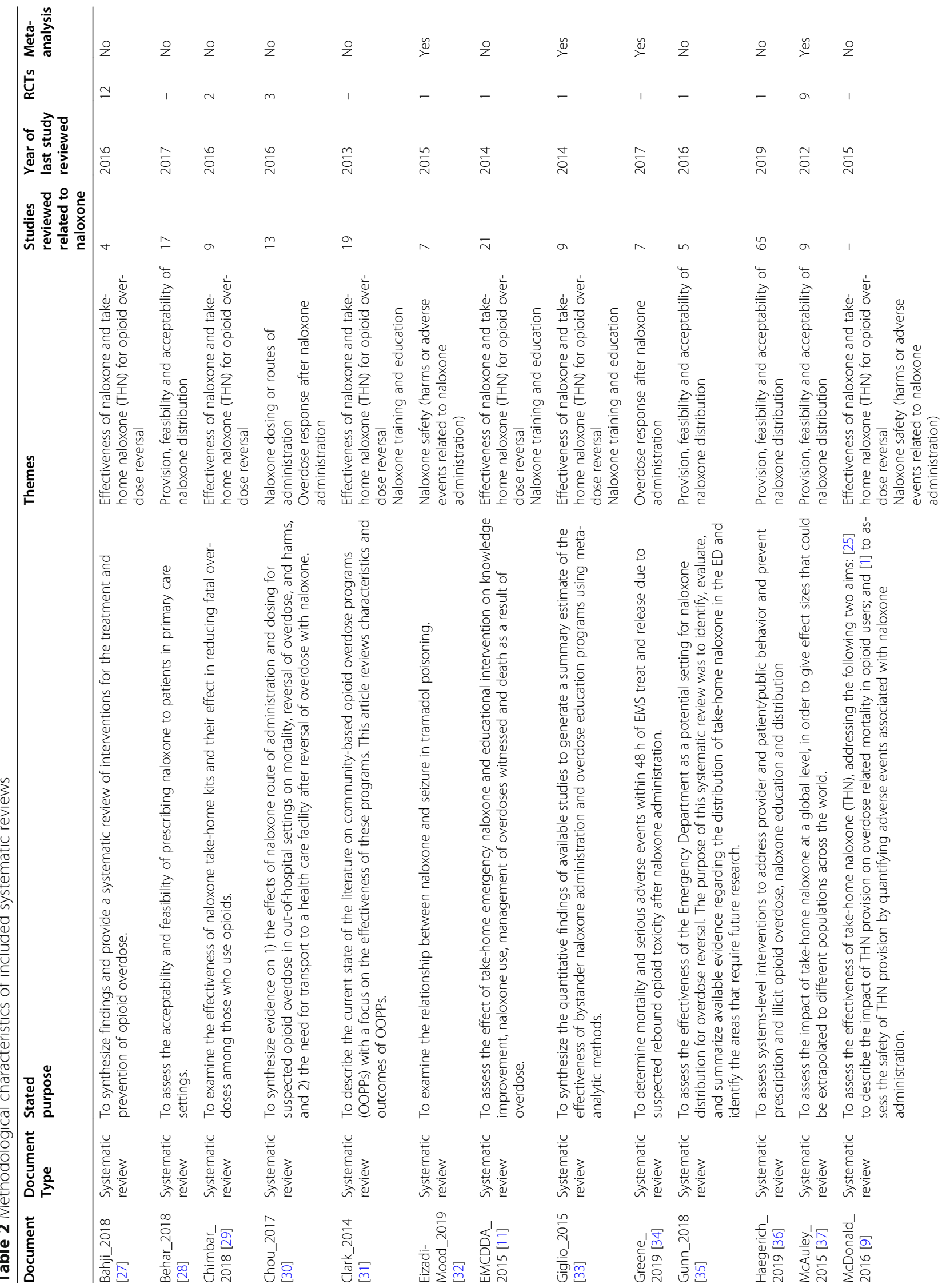




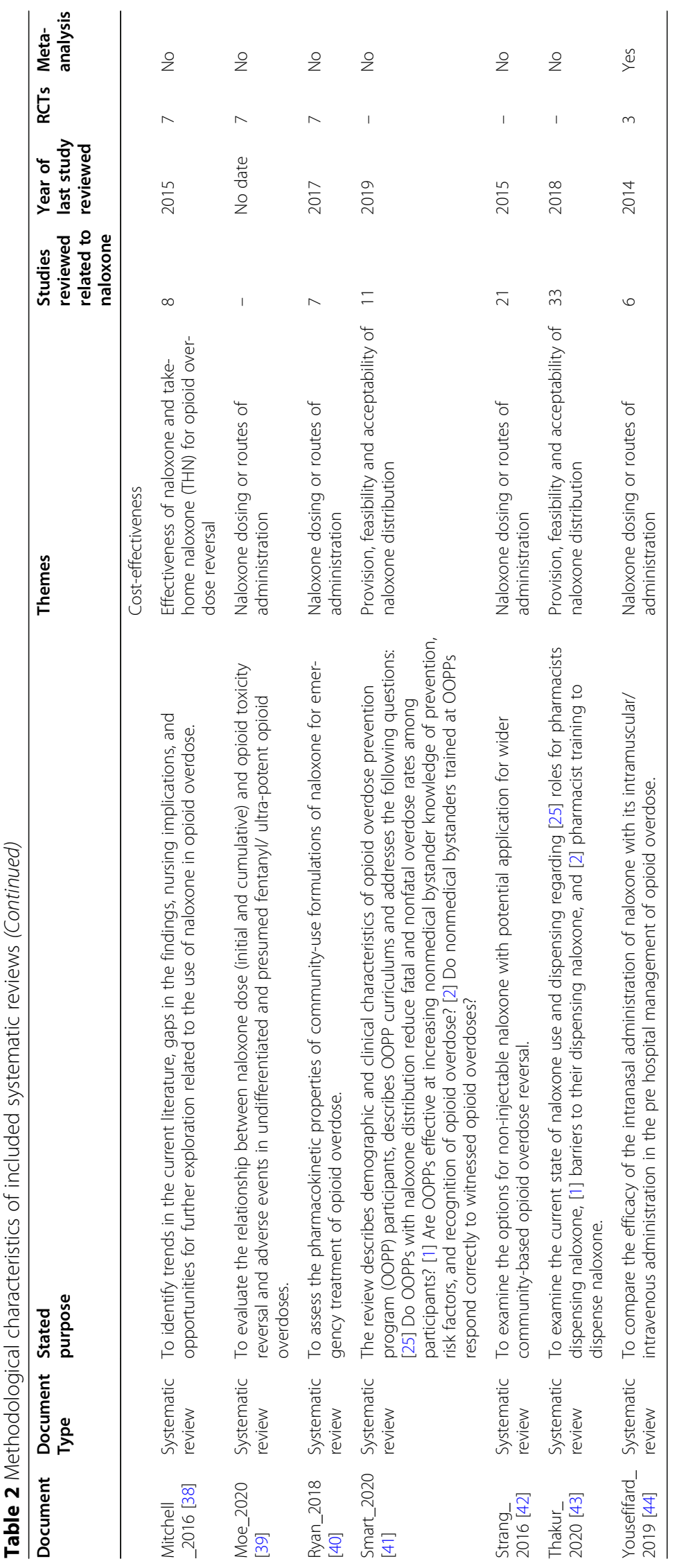




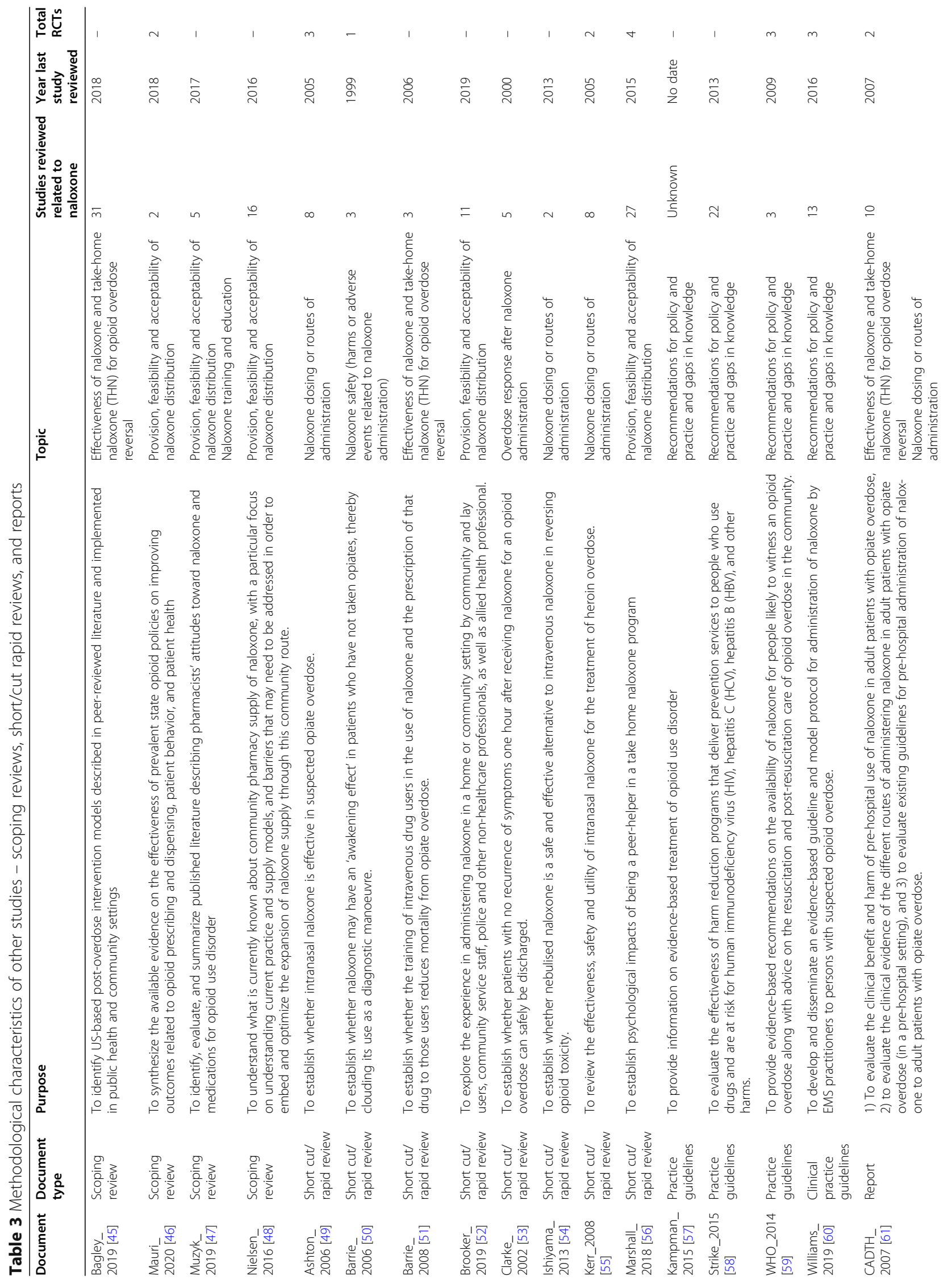




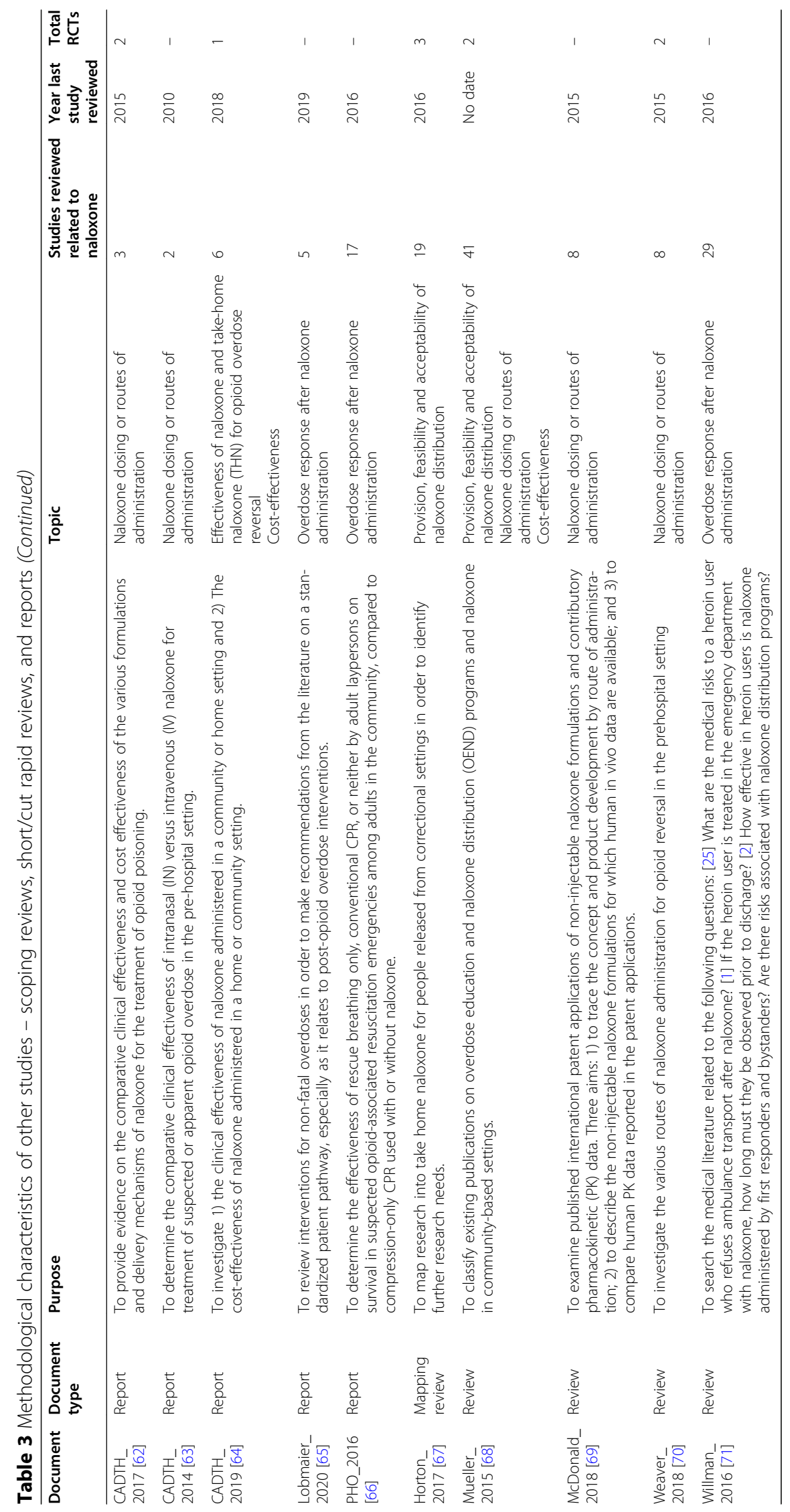


Table 4 Included literature by subject theme

\begin{tabular}{|c|c|c|}
\hline Subject themes & $\begin{array}{l}\text { Number of studies included } \\
(\%)^{*}\end{array}$ & Studies included \\
\hline Naloxone dosing or routes of administration & $14(29.8 \%)$ & $\begin{array}{l}{[30,39,40,42,44,49,54,55,61-63} \\
68-70]\end{array}$ \\
\hline Provision, feasibility and acceptability of naloxone distribution & $13(27.7 \%)$ & $\begin{array}{l}{[28,35-37,41,43,46-48,52,56,67} \\
68]\end{array}$ \\
\hline $\begin{array}{l}\text { Effectiveness of naloxone and take-home naloxone (THN) for opioid over- } \\
\text { dose reversal }\end{array}$ & $10(21.3 \%)$ & {$[9,11,27,29,31,33,38,45,51,61,64]$} \\
\hline Overdose response after naloxone administration & $6(12.8 \%)$ & {$[30,34,53,65,66,71]$} \\
\hline Naloxone training and education & $6(12.8 \%)$ & {$[11,31,33,36,47,51]$} \\
\hline Recommendations for policy, practice, and gaps in knowledge & $4(8.5 \%)$ & {$[57-60]$} \\
\hline $\begin{array}{l}\text { Naloxone safety (harm and adverse events related to naloxone } \\
\text { administration) }\end{array}$ & $3(6.4 \%)$ & {$[9,32,50]$} \\
\hline Cost-effectiveness & $3(6.4 \%)$ & {$[9,64,68]$} \\
\hline
\end{tabular}

*Percentages do not add up to $100 \%$ because some document subject themes overlap

administration by community and lay users, service staff, police and other non-healthcare professionals $[52,56]$.

A review by Haegerich et al. [36] examined available evidence related to naloxone delivery modalities including 1) state legislation and regulation, 2) prescription drug monitoring programs (PDMPs), 3) insurance strategies, 4) clinical guideline implementation, 5) provider education, 6) health system interventions, 7) naloxone education and distribution, 8) safe storage and disposal, 9) public education, 10) community coalitions, and 11) interventions employing public safety and public health collaborations.

Mueller et al. [68] also sought to understand the extent of available evidence related to provider willingness to prescribe naloxone as well as experiences and attitudes of potential bystanders sampled from service users of harm reduction programs.

Two studies looked at drug policy within the United States; a systematic review [41] investigated the association of naloxone access laws and naloxone prescribing and distribution and a scoping review [46] identified literature on legislative and administrative policy interventions that evaluated prescribing and dispensing, patient behaviour, or patient health. Studies related to naloxone access laws were included in this theme given their effect on delivery modalities and acceptability from the perspective of various stakeholders.

Finally, a systematic review by McAuley et al. [37] sought to understand what proportion of distributed naloxone is used to respond to overdose in order to inform naloxone supply needs. The authors used meta-analyses to estimate what proportion of those trained and supplied with naloxone will use it within a given time period.

\section{Naloxone dosing and route of administration}

We identified five systematic reviews focused on comparing the effectiveness between injectable (e.g., intravenous, subcutaneous, intramuscular) and noninjectable (e.g., intranasal, buccal, sublingual) naloxone routes of administration [30, 39, 40, 42, 44]. A final systematic review published in 2020 aimed to evaluate sufficient naloxone doses during an era of ultra-potent synthetic opioid use [39].

Another six non-systematic reviews examined topics related to routes of administration for opioid reversal. One review evaluated implications of different routes of administration for pharmacy practice (e.g., reasons for preferences) [70]. Another 'comprehensive review' performed an exploratory search of patent applications for non-injectable naloxone to expand knowledge on bioavailability of intravenous vs non-intravenous naloxone formulations [69]. The review by Mueller et al. also sought to identify evidence related to naloxone routes of administration, identifying a total of five controlled trials in pre-hospital settings comparing intranasal, intravenous, and intramuscular administration [68]. Three rapid reviews also aimed to identify evidence related to whether nebulized naloxone [54] and intranasal naloxone $[49,55]$ were effective alternatives to injectable formulations for overdose reversal.

The Canadian Agency for Drugs and Technologies in Health (CADTH) published three separate reports identified in the grey-literature comparing the clinical effectiveness of intranasal and intravenous naloxone for treatment of suspected opioid overdose [32, 49, 64].

\section{Naloxone safety - harms and adverse events related to naloxone administration}

One identified systematic review with meta-analysis focused on potential harms after naloxone administration [32], specifically reviewing literature related to whether naloxone increased the risk of seizures after treatment of tramadol poisoning. 


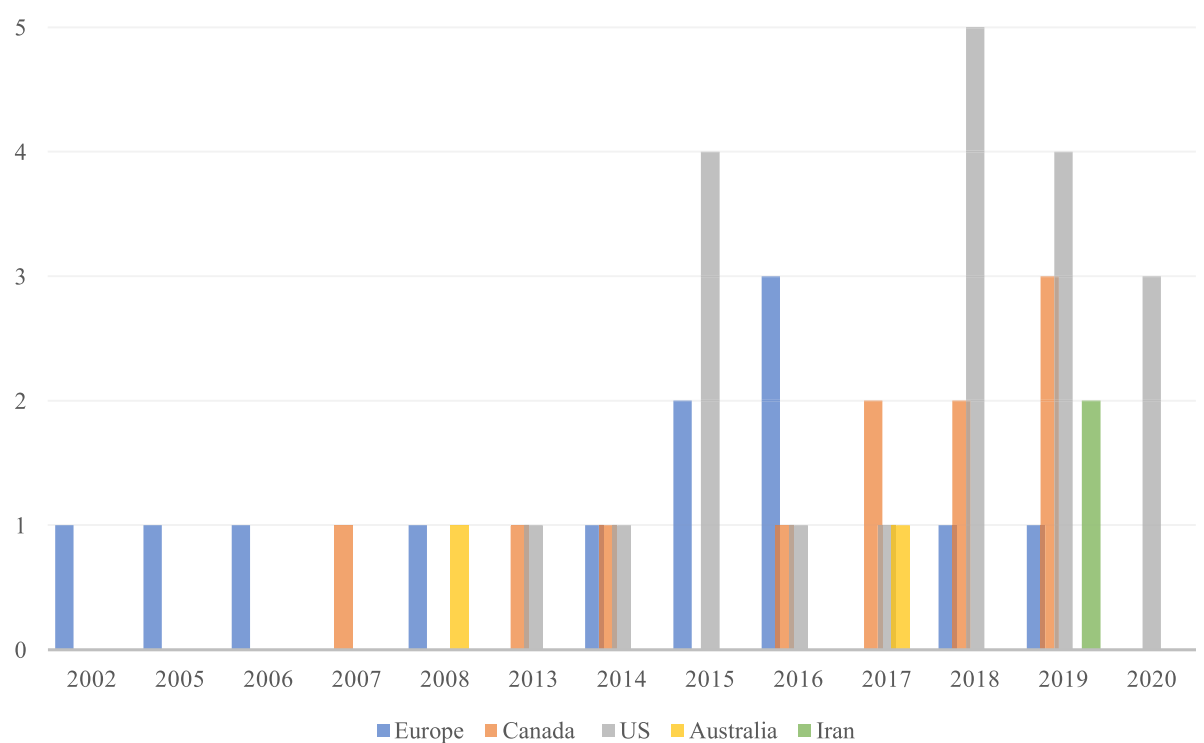

Fig. 2 Histogram of region of origin and date of published naloxone research syntheses

One rapid review aimed to establish evidence related to the effect of naloxone when used for patients with non-opioid toxicity. The review searched the literature to establish whether naloxone may have the same 'awakening effect' in patients with no reported recent opioid use [50].

A grey literature report by CADTH in 2017 reported on two unblinded randomized controlled articles comparing incidence of adverse events with naloxone administered intranasally using a mucosal atomizer and intramuscular naloxone, including agitation and/or aggression, nausea and/or vomiting, and headache [62].

\section{Overdose response following naloxone administration}

Two systematic reviews examined the evidence related to the need for transport to hospital after naloxone administration, based on mortality or serious adverse events after treatment $[30,72]$. One of the systematic reviews looked at naloxone administration by Emergency Medical Services (EMS) personnel, other health care providers, or laypersons [30] while the other looked exclusively at naloxone administration by EMS [72]. None of the primary articles compared outcomes between people transported and not transported to hospital [30]. Three more non-systematic review articles evaluated evidence related to the need for observation after treatment with naloxone $[65,73,74]$. A fourth evidence review examined the effectiveness of giving chest compression and/or rescue breaths after naloxone administration [66].

\section{Cost effectiveness}

While we did not identify any systematic reviews focused specifically on cost-effectiveness of naloxone or naloxone distribution, two systematic reviews examined cost-effectiveness as secondary outcome measures $[8,45]$. One of the two reported on separate modelling data from both the United States and Russia, and the other reported on the financial impact of intranasal naloxone compared to intramuscular forms [38]. Relying on the same two articles evaluated by McDonald et al., a review by Mueller et al. also examined the cost-effectiveness of naloxone distribution programs [68]. Two reports by $\mathrm{CADTH}$ attempted to synthesize evidence related to cost-effectiveness of naloxone distribution programs $[62,64]$.

\section{Naloxone education/training for bystanders}

One systematic review attempted to quantify the effect of naloxone training programs based on overall average scores between trained participants compared with untrained participants on tests that covered overdose prevention material (naloxone administration, overdose recognition, overdose response) [33]. Two additional systematic reviews also synthesized evidence on naloxone training and education as secondary outcomes including improvement in knowledge immediately after training [10, 38],

\section{Recommendations for policy and practice and gaps in knowledge}

Four practice guidelines were identified which used evidence syntheses to create recommendations for the use and/or distribution of naloxone. First, the World Health Organisation (WHO) published guidelines for community management of opioid overdose in 2014 [59]. For 
all key questions, the WHO assessed the quality of evidence based on Grading of Recommendations Assessment, Development and Evaluation (GRADE) criteria. Key questions included: 1) Should naloxone be distributed to people who are likely to witness an opioid overdose? 2) What formulation and dosage of naloxone should be used in the initial management of opioid overdose, including by lay responders, and in the prehospital setting? 3) Should the resuscitation response to suspected opioid overdose, including by layperson bystanders, be based on standard CPR or chest compression only CPR? 4) What should be the response to opioid overdose after the administration of naloxone and successful reversal of opioid overdose in the community, including by lay first responders?

In 2015, a Working Group on Best Practice for Harm Reduction Programs in Canada created recommendations for the use of naloxone in the event of an opioid overdose [58]. Additionally in 2015, the American Society of Addiction Medicine (ASAM) created a national practice guideline for the use of medications in the treatment of addiction involving opioid use, intended for clinicians involved in evaluating patients and providing authorization for pharmacological treatments at any level [57]. As it relates to the use of naloxone, the ASAM addressed naloxone administration in cases of opioid overdose (including for pregnant women), naloxone provision for patients being treated for opioid use disorder (OUD) and their families, and administration of naloxone by first responders. In 2019, Williams et al. published evidence-based guidelines for Emergency Medical Service (EMS) administration of naloxone [60], including route of administration.

\section{Discussion}

This review scoped the existing literature for evidence syntheses related to the use and distribution of naloxone for reversal of opioid overdose in community settings. We identified a total of 47 articles, including 20 systematic reviews. We found that the majority of evidence syntheses related to naloxone evaluated the effectiveness of naloxone and THN programs in reducing opioid overdose mortality, examined optimal dosing or routes of administration for opioid overdose reversal, and documented barriers and facilitators to THN provision, feasibility and acceptability. Fewer evidence syntheses evaluated harms and adverse events related to naloxone administration, overdose response following naloxone administration, costeffectiveness of naloxone distribution programs, and naloxone administration training strategies, and recommendations for policy and practice related to naloxone use and distribution.
While most review articles relied on observational data, there appears to be a variety of evidence addressing THN and overdose reversal and or overdose mortality. A number of systematic reviews have now also collated evidence related to available naloxone administration methods and optimal doses, both for contexts before and after the emergence of potent synthetic opioids (like fentanyl) on the illicit market, which may be used to inform naloxone provision and use.

Less of the evidence related to specific operational aspects or optimization of THN programs. Available distribution models, feasibility, and acceptability for naloxone distribution is dependent on jurisdiction and setting. For example, some provinces in Canada currently require pharmacist intervention for naloxone distribution, many jurisdictions in the United States require a prescription [45], while other provinces in Canada list naloxone as an unscheduled drug (drugs which can be sold without professional distribution) [12]. Given the different contexts and laws related to opioid and naloxone scheduling and availability [75], strategies related to distribution, feasibility, and acceptability will require jurisdiction-specific evidence.

In addition, only three studies examined evidence related to cost-effectiveness as secondary outcomes. Only one systematic review examined training parameters for naloxone administration, and one systematic review conducted, was related to adverse events following naloxone administration. Future evidence syntheses on these topics would help inform policy and practice.

The goal of this study was to identify gaps in the current evidence needed to inform clinical and operational guidance. Table 5 describes gaps in the literature by subject theme. While this study identified four best practice guideline recommendations published since 2014, three of these created recommendations that were intended for clinicians [57], EMS [60], or program administrators [58] rather than community members. In 2014, the World Health Organisation attempted to create best practice guidelines for community management of opioid overdose that would be applicable across jurisdictions, though recommendations relied on the scant evidence available at that time and should be updated [59].

To our knowledge, this is the first scoping umbrella review conducted to examine evidence related to the use and distribution of naloxone by bystanders and community members in response to suspected opioid overdose. As opioid overdose deaths continue to rise and THN programs continue to expand in Canada, the United States, and Europe, this review will help inform the need for future research and ensure evidence based THN program development and expansion. 


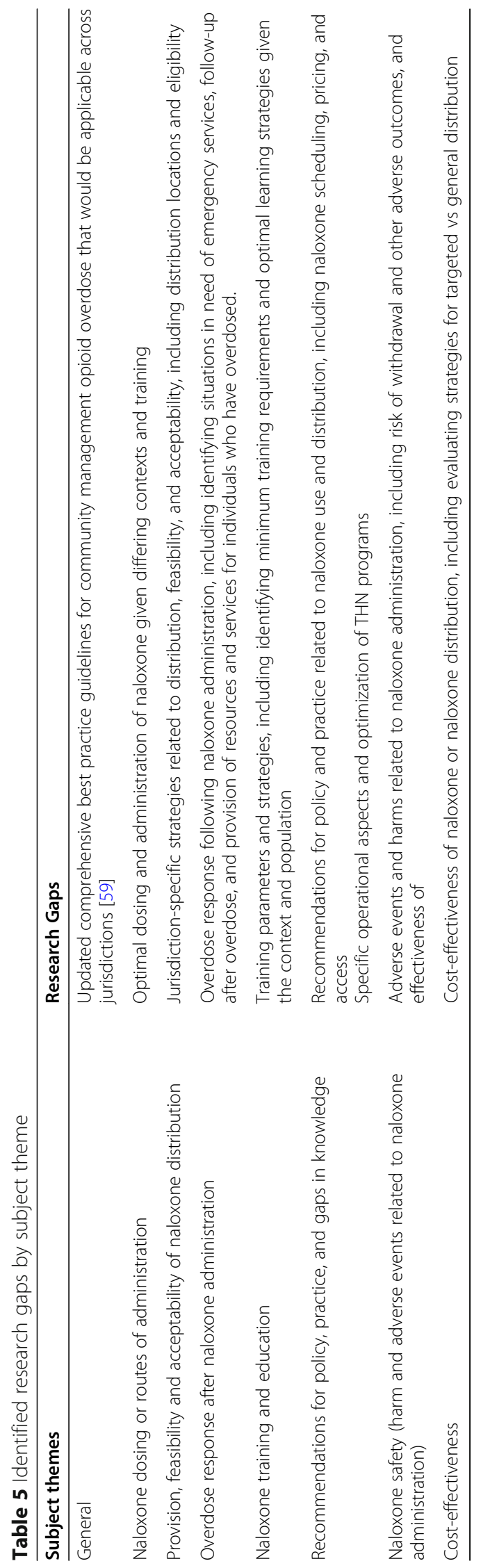




\section{Conclusions}

There are several limitations associated with this study. Most of the evidence identified in the systematic reviews relied on observational data. Logistical and ethical issues related to conducting experimental trials in patients at risk of dying from opioid overdoses will likely continue to preclude the establishment of opioid-overdose interventions based on Randomized Controlled Trials (RCT) data. While we attempted to control for quality by limiting our search to studies or documents which used systematic methods to search the literature for evidence related to naloxone, this study did not attempt to provide a synthesis of findings or a quality appraisal of the included literature. Further, our group is based in Canada, and many of the grey literature products identified through targeted websites and expert contacts may be biased towards this region. Scholarly literature searches were also limited to documents in English or French, which may also limit the scope of this study as language of publication limits the geographical range of studies reviewed. Further assessment of included syntheses should be made before they are relied upon for developing recommendations or program amendments.

\section{Acknowledgements}

The authors would like to thank Ursula Ellis who generously offered her expertise as a research librarian in the development of search terms and criteria for grey and scholarly research databases.

\section{Authors' contributions}

Authors AMB, DD, JN, KS, FA, TEM, PL, KR, JAB contributed to study conception and design. Authors $\mathrm{AMB}$ and $\mathrm{JN}$ completed data extraction. Authors KS and DD validated extracted data. Author AMB wrote the manuscript and MF applied revisions. All authors contributed to reviewing and editing the manuscript.

\section{Funding}

The authors acknowledge funding from Canadian Institutes of Health Research (CIHR) for the Canadian Research Initiative in Substance Misuse (CRISM) Implementation Science Program on Opioid Interventions and Services (OCC- 154821).

\section{Availability of data and materials}

All data is publicly accessible through scholarly and grey literature search engines.

\section{Declarations}

\section{Ethics approval and consent to participate}

This study uses secondary analysis of existing research data and is exempt from ethics review under Article 2.4 of the Canadian Tri-Council Policy Statement (TCPS2) for the ethical conduct of research involving humans and/or human biological materials [25].

\section{Competing interests}

Authors JN, KS, DD, FA and TEM have no conflicts to declare. Author KR works for Alberta Health Services (AHS), the agency responsible for administering Alberta's take-home naloxone program. Part of authors AMB, $M F$, and JB's salary comes from the British Columbia Centre for Disease Control (BCCDC), the agency responsible for administering the British Columbia take-home naloxone program. Author PL is a co-investigator on another study with in-kind contribution of naloxone from Adapt Pharma. The company is not involved in the design or conduct of the study.

\section{Author details}

${ }^{1}$ BC Centre for Disease Control, Vancouver, BC, Canada. ${ }^{2}$ Faculty of Medicine, University of British Columbia, Vancouver, BC, Canada. ${ }^{3}$ Institute for Mental Health Policy Research, Centre for Addiction and Mental Health (CAMH), London, ON, Canada. ${ }^{4}$ Department of Epidemiology and Biostatistics, Western University, London, ON, Canada. ${ }^{5}$ Dalla Lana School of Public Health, University of Toronto, Toronto, ON, Canada. ${ }^{6}$ Public Health Ontario (PHO), Toronto, ON, Canada. ${ }^{7}$ Alberta Health Services (AHS), Edmonton, AB, Canada. ${ }^{8}$ University of Alberta, Edmonton, $A B$, Canada. ${ }^{9}$ University of Calgary, Calgary, $\mathrm{AB}$, Canada. ${ }^{10} \mathrm{School}$ of Population and Public Health, University of British Columbia, Vancouver, BC, Canada.

Received: 19 December 2020 Accepted: 24 February 2021 Published online: 26 March 2021

References

1. Opioid overdose [Internet]. [cited 2020 Oct 18]. Available from: https://www. who.int/news-room/fact-sheets/detail/opioid-overdose.

2. World Health Organisation. Opioid overdose [Internet]. Opioid overdose. 2020 [cited 2020 Oct 18]. Available from: https://www.who.int/news-room/ fact-sheets/detail/opioid-overdose.

3. Wilson N, Kariisa M, Seth P, Smith H, Davis NL. Drug and Opioid-Involved Overdose Deaths — United States, 2017-2018. MMWR Morb Mortal Wkly Rep [Internet]. 2020 [cited 2020 Nov 30];69. Available from: https://www.cdc. gov/mmwr/volumes/69/wr/mm6911a4.htm

4. Lisa B, Jessica H. Evidence synthesis - the opioid crisis in Canada: a national perspective. Health Promot Chronic Dis Prev Can Res Policy Pract. 2018; 38(6):224-33.

5. Rudd RA, Aleshire N, Zibbell JE, Gladden RM. Increases in drug and opioid overdose deaths--United States, 2000-2014. MMWR Morb Mortal Wkly Rep. 2016;64(50-51):1378-82.

6. Pathan H, Williams J. Basic opioid pharmacology: an update. Br J Pain. 2012; 6(1):11-6.

7. Kim HK, Nelson LS. Reducing the harm of opioid overdose with the safe use of naloxone : a pharmacologic review. Expert Opin Drug Saf. 2015;14(7): 1137-46.

8. Doyon S, Aks SE, Schaeffer S. Expanding access to naloxone in the United States. J Med Toxicol Off J Am Coll Med Toxicol. 2014;10(4):431-4.

9. McDonald R, Strang J. Are take-home naloxone programmes effective? Systematic review utilizing application of the Bradford Hill criteria. Addict Abingdon Engl. 2016;111(7):1177-87.

10. Doyon S, Aks SE, Schaeffer S. Expanding access to naloxone in the United States. J Med Toxicol. 2014;10(4):431-4.

11. EMCDDA (European Monitoring Centre for Drugs and Drug Addiction). Preventing fatal overdoses: a systematic review of the effectiveness of take-home naloxone [Internet]. EMCDDA (European Monitoring Centre for Drugs and Drug Addiction); 2015 [cited 2020 May 5]. Available from: http://www.emcdda.europa. eu/attachements.cfm/att 234376 EN TDAU14009ENN.web_pdf.

12. Amina Moustaqim-Barrette, Tara Elton-Marshall, Pamela Leece, Caroele Morissette, Katherine Rittenbach, Jane Buxton. Environmental Scan Naloxone Access and Distribution in Canada. 2019 Jun 30; Available from: https://open.library.ubc.ca/media/stream/pdf/52383/1.0379400/5

13. Irvine MA, Buxton JA, Otterstatter M, Balshaw R, Gustafson R, Tyndall M, et al. Distribution of take-home opioid antagonist kits during a synthetic opioid epidemic in British Columbia, Canada: a modelling study. Lancet Public Health. 2018;3(5):e218-25.

14. Irvine MA, Kuo M, Buxton JA, Balshaw R, Otterstatter M, Macdougall L, et al. Modelling the combined impact of interventions in averting deaths during a synthetic-opioid overdose epidemic. Addict Abingdon Engl. 2019;114(9): 1602-13.

15. Irvine MA, McGowan R, Hammond K, Davison C, Coombs D, Gilbert M. The role of mathematical modelling in aiding public health policy decisionmaking: a case study of the BC opioid overdose emergency. Int J Drug Policy. 2019;9014759:102603.

16. Arksey H, O'Malley L. Scoping studies: towards a methodological framework. Int J Soc Res Methodol. 2005:8(1):19-32.

17. Levac D, Colquhoun H, O'Brien KK. Scoping studies: advancing the methodology. Implement Sci IS. 2010;5:69.

18. Tricco AC, Lillie E, Zarin W, O'Brien KK, Colquhoun H, Levac D, et al. PRISMA Extension for Scoping Reviews (PRISMA-SCR): Checklist and Explanation. Ann Intern Med. 2018 02;169(7):467-73. 
19. Higgins J, Green S. Cochrane Handbook for Systematic Reviews of Interventions [Internet]. 2011 [cited 2020 May 28]. Available from: /handbook/current

20. Godin K, Stapleton J, Kirkpatrick SI, Hanning RM, Leatherdale ST. Applying systematic review search methods to the grey literature: a case study examining guidelines for school-based breakfast programs in Canada. Syst Rev. 2015;4(1):138.

21. World Drug Report 2019 [Internet]. United Nations publication; 2019 [cited 2020 Nov 6]. Available from: https://wdr.unodc.org/wdr2019/

22. Courraud J. Zotero: A free and open-source reference manager. Med Writ. 2014;23(1):46-8

23. Covidence systematic review software, Veritas Health Innovation, Melbourne, Australia. Available at www.covidence.org.

24. Paul A. Harris, Robert Taylor, Robert Thielke, Jonathon Payne, Nathaniel Gonzalez, Jose G. Conde, Research electronic data capture (REDCap) - A metadata-driven methodology and workflow process for providing translational research informatics support. J Biomed Inform. 2009;42(2):37781.

25. Government of Canada IAP on RE. Tri-Council Policy Statement: Ethical Conduct for Research Involving Humans - TCPS 2 (2018) - Chapter 2: Scope and Approach [Internet]. 2019 [cited 2020 Aug 4]. Available from: https://ethics.gc.ca/eng/tcps2-eptc2_2018_chapter2-chapitre2.html

26. R Core Team. R: A language and environment for statistical computing. R Foundation for Statistical Computing, Vienna, Austria. 2014. http://www.Rproject.org/.

27. Bahji A, Bajaj N. Opioids on trial: a systematic review of interventions for the treatment and prevention of opioid overdose. Can J Addict. 2018;9(1):26-33.

28. Behar E, Bagnulo R, Coffin PO. Acceptability and feasibility of naloxone prescribing in primary care settings: a systematic review. Prev Med. 2018; 114:79-87.

29. Chimbar L, Moleta Y. Naloxone effectiveness: a systematic review. J Addict Nurs. 2018;29(3):167-71.

30. Chou R, Korthuis PT, McCarty D, Coffin PO, Griffin JC, Davis-O'Reilly C, et al. Management of Suspected Opioid Overdose with Naloxone in out-ofhospital settings: a systematic review. Ann Intern Med. 2017;167(12):867-75.

31. Clark AK, Wilder CM, Winstanley EL. A systematic review of community opioid overdose prevention and naloxone distribution programs. J Addict Med. 2014;8(3):153-63.

32. Eizadi-Mood N, Ghandehari M, Mansourian M, Sabzghabaee AM, Samasamshariat S, Sadeghi E. Risk of seizure after naloxone therapy in acute tramadol poisoning: a systematic review with meta-analysis. Int J Prev Med. 2019;10(101535380):183.

33. Giglio RE, Li G, DiMaggio CJ. Effectiveness of bystander naloxone administration and overdose education programs: a meta-analysis. Inj Epidemiol. 2015;2(1):10.

34. Greene JA, Deveau BJ, Dol JS, Butler M. The prevalence of mortality due to rebound toxicity after "treat and release" practices in prehospital opiate overdose care: a systematic review. Can J Hosp Pharm. 2018;71(1):82.

35. Gunn AH, Smothers ZPW, Schramm-Sapyta N, Freiermuth CE, MacEachern M, Muzyk AJ. The emergency department as an opportunity for naloxone distribution. West J Emerg Med. 2018;19(6):1036-42.

36. Haegerich TM, Jones CM, Cote P-O, Robinson A, Ross L. Evidence for state, community and systems-level prevention strategies to address the opioid crisis. Drug Alcohol Depend. 2019;204(ebs, 7513587):107563.

37. McAuley A, Aucott $L$, Matheson C. Exploring the life-saving potential of naloxone: a systematic review and descriptive meta-analysis of take home naloxone (THN) programmes for opioid users. Int J Drug Policy. 2015;26(12): 1183-8.

38. Mitchell KD, Higgins LJ. Combating opioid overdose with public access to naloxone. J Addict Nurs. 2016;27(3):160-79.

39. Moe J, Godwin J, Purssell R, O'Sullivan F, Hau JP, Purssell E, et al. Naloxone dosing in the era of ultra-potent opioid overdoses: a systematic review. CJEM. 2020;22(2):178-86.

40. Ryan SA, Dunne RB. Pharmacokinetic properties of intranasal and injectable formulations of naloxone for community use: a systematic review. Pain Manag. 2018:8(3):231-45

41. Smart R, Pardo B, Davis CS. Systematic review of the emerging literature on the effectiveness of naloxone access laws in the United States. Addiction. 2021;116(1):6-17.

42. Strang J, McDonald R, Alqurshi A, Royall P, Taylor D, Forbes B. Naloxone without the needle - systematic review of candidate routes for non- injectable naloxone for opioid overdose reversal. Drug Alcohol Depend. 2016;163:16-23.

43. Thakur T, Frey M, Chewning B. Pharmacist roles, training, and perceived barriers in naloxone dispensing: a systematic review. JAPhA. 2020;60(1):178-94

44. Yousefifard M, Vazirizadeh-Mahabadi MH, Neishaboori AM, Alavi SNR, Amiri M, Baratloo A, et al. Intranasal versus Intramuscular/Intravenous Naloxone for Pre-hospital Opioid Overdose: A Systematic Review and Meta-analysis. Adv J Emerg Med [Internet]. 201916 [cited 2020 Aug 18];4(2). Available from: https://www.ncbi.nlm.nih.gov/pmc/articles/PMC7163267/

45. Bagley SM, Schoenberger SF, Waye KM, Walley AY. A scoping review of post opioid-overdose interventions. Prev Med. 2019;128(pm4, 0322116): 105813.

46. Mauri Al, Townsend TN, Haffajee RL. The Association of State Opioid Misuse Prevention Policies with Patient- and Provider-Related Outcomes: a scoping review. Milbank Q. 2020;98(1):57-105.

47. Muzyk A, Smothers ZPW, Collins K, MacEachern M, Wu L-T. Pharmacists' attitudes toward dispensing naloxone and medications for opioid use disorder: a scoping review of the literature. Subst Abuse. 2019;40(4):476-83.

48. Nielsen S, Van Hout MC. What is known about community pharmacy supply of naloxone? A scoping review. Int J Drug Policy. 2016;32:24-33.

49. Ashton $\mathrm{H}$, Hassan Z. Best evidence topic report. Intranasal naloxone in suspected opioid overdose. EMJ. 2006;23(3):221-3.

50. Barrie J, May G. Towards evidence-based emergency medicine: best BETs from the Manchester Royal Infirmary. Diagnosis of drug overdose by rapid reversal with naloxone. EMJ. 2006;23(11):874-5.

51. Barrie J. Towards evidence based emergency medicine: best BETs from the Manchester Royal Infirmary. BET 3. Training and prescription of naloxone for personal use in overdose for opiate addicts. EMJ. 2008;25(10):688-9.

52. Brooker A-S, Farrah K. 2019;

53. Clarke S, Herren K. Towards evidence based emergency medicine: best BETs from the Manchester Royal Infirmary. Oral or intravenous antidote for paracetamol overdose. Emerg Med J EMJ. 2002;19(3):247-8.

54. Ishiyama D. Bet 3 : is nebulised naloxone effective in opioid overdose? Emerg Med J. 2013;30(10):860.

55. Kerr D, Dietze P, Kelly AM. Intranasal naloxone for the treatment of suspected heroin overdose. Addict Abingdon Engl. 2008;103(3):379-86.

56. Marshall C, Perreault M, Archambault L, Milton D. Experiences of peertrainers in a take-home naloxone program: results from a qualitative study. Int J Drug Policy. 2017;41:19-28.

57. Kampman K, Cunningham C, Fishman MJ, Gordon A, Nordstrom B, Woody $\mathrm{G}$, et al. National Practice Guideline for the Use of Medications in the Treatment of Addiction Involving Opioid Use 2015;66.

58. Strike C., Watson T.M., Hopkins S., Gohil H., Leece P. Best practice recommendations for canadian harm reduction programs that provide service to people who use drugs and are at risk for HIV, HCV, and other harms. Can J Infect Dis Med Microbiol. 2014;25(SUPPL. SA):85A.

59. WHO World Health Organisation. Community management of opioid overdose [Internet]. Geneva, Switzerland: World Health Organisation (WHO); 2014 [cited 2020 May 5]. Available from: https://www.who.int/publicationsdetail/9789241548816

60. Williams K, Lang ES, Panchal AR, Gasper JJ, Taillac P, Gouda J, et al. Evidence-based guidelines for EMS Administration of naloxone. Prehospital Emerg Care Off J Natl Assoc EMS Physicians Natl Assoc State EMS Dir. 2019; 23(6):749-63.

61. CADTH. Pre-Hospital Use of Naloxone in Adults with Suspected Opiate Overdose: Guidelines and Clinical Effectiveness [Internet]. CADTH.ca. 2007 [cited 2020 May 5]. Available from: https://www.cadth.ca/pre-hospital-use-na loxone-adults-suspected-opiate-overdose-guidelines-and-clinicaleffectiveness

62. CADTH. Intranasal and Intramuscular Naloxone for Opioid Overdose in the Pre-Hospital Setting: A Review of Comparative Clinical and CostEffectiveness, and Guidelines [Internet]. CADTH.ca. 2017 [cited 2020 May 5]. Available from: https://www.cadth.ca/intranasal-and-intramuscular-naloxoneopioid-overdose-pre-hospital-setting-review-comparative

63. CADTH. Intranasal versus Intravenous Naloxone for Opioid Overdose in the Pre-Hospital Setting: Comparative Clinical Effectiveness [Internet]. CADTH.ca. 2014 [cited 2020 Jul 9]. Available from: file://Users/aminamoustaqimbarrette/Downloads/CADTH3 2014\%20(2).pdf

64. CADTH. Administration of Naloxone in a Home or Community Setting: A Review of the Clinical Effectiveness, Cost-effectiveness, and Guidelines [Internet]. Ottawa (ON): Canadian Agency for Drugs and Technologies in 
Health; 2019 [cited 2020 Jul 9]. (CADTH Rapid Response Reports). Available from: http://www.ncbi.nlm.nih.gov/books/NBK554744/

65. Lobmaier P, Bukten A, Clausen T. Aftercare for overdose survivors during the first hours and days following an intoxication: A review of the literature Institutt for klinisk medisin. 2020 [cited 2020 May 28]; Available from: https:// www.med.uio.no/klinmed/forskning/sentre/seraf/publikasjoner/rapporter/2 020/aftercare-for-overdose-survivors-during-the-first-html

66. Public Health Ontario. Evidence Brief: Evidence on rescue breathing or chest compressions in local naloxone programs [Internet]. Ontario: Public Health Ontario; 2016 Dec [cited 2020 May 5] p. 11. Available from: https://www. publichealthontario.ca/-/media/documents/E/2017/eb-cpr-naloxone-progra ms.pdf?la=en.

67. Horton M, McDonald R, Green TC, Nielsen S, Strang J, Degenhardt L, et al. A mapping review of take-home naloxone for people released from correctional settings. Int J Drug Policy [Internet]. 2017 Aug 1:46. Available from: http://www.epistemonikos.org/documents/33f42e44e047928fbff44 57cf49dfeaf3961eac3

68. Mueller SR, Walley AY, Calcaterra SL, Glanz JM, Binswanger IA. A review of opioid overdose prevention and naloxone prescribing: implications for translating community programming into clinical practice. Subst Abuse. 2015;36(2):240-53.

69. McDonald R, Danielsson Glende $\varnothing$, Dale O, Strang J. International patent applications for non-injectable naloxone for opioid overdose reversal: exploratory search and retrieve analysis of the PatentScope database. Drug Alcohol Rev. 2018;37(2):205-15.

70. Weaver L, Palombi L, Bastianelli KMS. Naloxone Administration for Opioid Overdose Reversal in the Prehospital setting: implications for pharmacists. J Pharm Pract. 2018;31(1):91-8.

71. Willman MW, Liss DB, Schwarz ES, Mullins ME. Do heroin overdose patients require observation after receiving naloxone? Clin Toxicol Phila Pa. 2017; 55(2):81-7.

72. Greene JA, Deveau BJ, Dol JS, Butler MB. Incidence of mortality due to rebound toxicity after 'treat and release' practices in prehospital opioid overdose care: a systematic review. Emerg Med J. 2019;36(4):219-24.

73. Clarke S, Herren K. Oral or intravenous antidote for paracetamol overdose. EMJ. 2002;19(3):247-8.

74. Willman MW, Liss DB, Schwarz ES, Mullins ME. Do heroin overdose patients require observation after receiving naloxone? Clin Toxicol. 2017;55(2):81-7.

75. Degenhardt L, Charlson F, Mathers B, Hall WD, Flaxman AD, Johns N, et al. The global epidemiology and burden of opioid dependence: results from the global burden of disease 2010 study. Addiction. 2014;109(8):1320-33.

\section{Publisher's Note}

Springer Nature remains neutral with regard to jurisdictional claims in published maps and institutional affiliations.

Ready to submit your research? Choose BMC and benefit from:

- fast, convenient online submission

- thorough peer review by experienced researchers in your field

- rapid publication on acceptance

- support for research data, including large and complex data types

- gold Open Access which fosters wider collaboration and increased citations

- maximum visibility for your research: over $100 \mathrm{M}$ website views per year

At $\mathrm{BMC}$, research is always in progress.

Learn more biomedcentral.com/submissions 